\title{
Needle aspiration of the breast with immediate reporting of material
}

\author{
HELEN L D DUGUID, R A B WOOD, A D IRVING, P E PREECE, A CUSCHIERI
}

British Medical fournal, 1979, 2, 185-187

\section{Summary and conclusions}

Needle aspiration with immediate cytological reporting has been practised in a breast clinic for one year. Patients benefit by receiving immediately the provisional diagnosis and, when indicated, appointments for metastatic surveys. Close co-operation between surgeon and cytologist has resulted in increased skill in aspiration, better preparation of samples, and greater accuracy in interpretation of reports.

Since $5 \%$ of clinically benign lesions have proved malignant, even on immediate reporting, we would recommend cytological examination of all breast lumps.

\section{Introduction}

In a newly established breast clinic preliminary use of aspiration cytology ${ }^{1-3}$ gave an unacceptably high incidence of false-negative reports and unsatisfactory preparations. These were apparently due to poor aspiration technique and faulty preparation of slides. ${ }^{4}$ Accordingly it was arranged that a cytologist should prepare slides at the clinic. Now, using the Diff Quik rapid staining method, a provisional report is given within five minutes of aspiration. If the preparation is found to be unsatisfactory aspiration is immediately repeated.

Results obtained during the first year of this procedure have been analysed, with particular emphasis on finding reasons for false-negative and unsatisfactory reports. The value of aspiration cytology in patient management, the usefulness of which was recently questioned, ${ }^{5}$ has been assessed prospectively.

\section{Material and methods}

All patients attending the breast clinic in whom a lump or thickening was palpable were subjected to breast aspiration as part of the physical examination.

\section{ASPIRATION TECHNIQUE}

A $10 \mathrm{ml}$ disposable syringe is fitted into a Cameco syringe pistolholder (Cameco A6 Täbyvagen 71-180, 10 Enebybang, Sweden)

\footnotetext{
Department of Surgery, Ninewells Hospital and Medical School, Dundee DD1 9SY, UK

HELEN L D DUGUID, MD, FRCPATH, consultant pathologist

R A B WOOD, MRCP, FRCS, senior lecturer in surgery

A D IRVING, CHM, FRCs, lecturer in surgery

$P$ E PREECE, MB, FRCS, senior lecturer in surgery

A CUSCHIERI, MD, CHM, professor of surgery
}

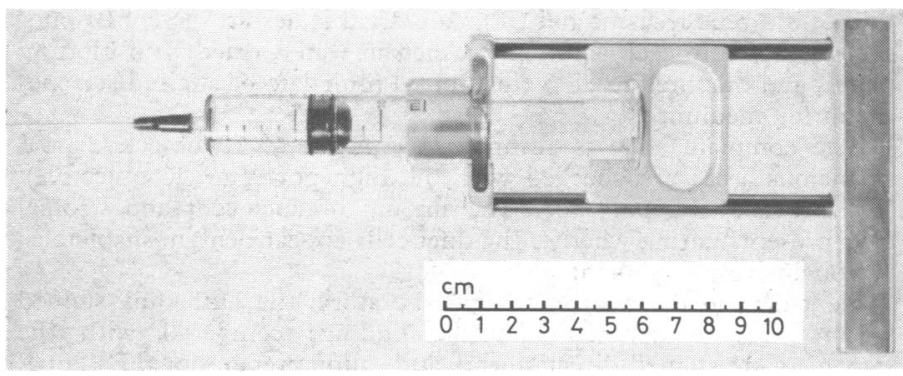

FIG 1-A Cameco syringe pistol-holder modified to hold disposable syringes.

modified by the medical physics department (fig 1 ) so that it can be used with the available disposable syringes. The use of the syringe holder allows constant suction to be maintained by a single hand holding the syringe. It is fitted with a No 21 Gauge (green hub) $0.8 \mathrm{~mm}$ diameter needle. Prior wetting of the needle lumen and syringe nozzle by sterile saline containing $10 \mathrm{U}$ of heparin $/ \mathrm{ml}$ prevents cell loss from aspirated material adhering to the needle wall. This does not interfere with smear preparation or staining provided that any excess saline-heparin solution is blown out before the aspirate is taken. After disinfection of the skin, a local anaesthetic may be used provided it is not allowed to contaminate the aspirate. The lump is steadied with one hand and the needle advanced through the skin to the edge of the lesion. The needle point is then used as a probe ${ }^{6}{ }^{6}$ and suction is applied when firm or hard tissue is felt. With suction maintained, the needle is then inserted carefully into three different areas of the mass and moved backwards and forwards up to five times. Rotating the needle helps dislodge a portion of tissue if the tumour is very hard. ${ }^{6}$ As the needle is withdrawn from the mass, suction is either maintained or slowly reduced.

This procedure, which should not be hurried, takes an average time of two minutes. The material obtained fills the lumen of the needle and usually appears as a drop at the nozzle of the syringe. Occasionally, aspirations from carcinomas are heavily bloodstained. When this occurs, aspiration is repeated from a different angle. If, on occasion, the needle lumen is blocked by a plug of aspirate, this is always examined.

When a cyst is aspirated, the material is expelled into a saline/ alcohol fixative for later examination unless it is bloodstained, in which case the last drop is examined on direct smear.

PREPARATION OF MATERIAL

The needle and syringe are handed to the cytologist, who prepares smears in the same room. While the aspiration is being taken, several slides with sand-blasted ends are polished and marked in pencil with the patient's name and unit number. The needle is removed from the syringe and the plunger pulled back to its fullest extent. The needle is then reconnected and the aspirate blown sharply on to one or two slides. The procedure is repeated until no more material can be obtained.

If excess blood or tissue fluid is present it is sucked back from the slide, leaving a predominance of tissue fragments. A squash prepara- 
tion is then made between the flat surfaces of two slides to obtain a monolayer of cells. Half of the slides are air dried in preparation for Diff Quik staining while the remainder are spray-fixed with Adams Spray Cyte in preparation for Papanicolaou staining.

Finally, the syringe and needle are flushed out several times into $10 \mathrm{ml}$ of $20 \%$ alcohol and $6 \%$ acetic acid in physiological saline, provided in disposable centrifuge tubes. This is spun down next day and the deposit pipetted on to slides coated with $0.1 \%$ poly-1-lysine solution, which fixes the material to the slides by electrostatic attraction.?

\section{STAINING PROCEDURE AND PROVISIONAL REPORTING}

Staining procedure and provisional reporting take place in a small laboratory adjacent to the examination rooms. The Diff Quik method (Harleco American Hospital Supply Corporation, Station Road, Didcot, Oxfordshire OX11 7NP) is mainly used for the rapid diagnosis of blood films in haematology outpatient clinics and gives results similar to Giemsa stain. It consists of a fixative solution, a red xanthene dye, and a blue thiazine dye. The air-dried slides are given 10 onesecond dips into each solution, washed in water, dried with blotting paper, and mounted in BPS (di-n butyl phthalate plasticised styrene) mounting medium.

The complete slide is scanned low power ( $\times 10$ objective) and suspicious areas are checked with the high power ( $\times 40$ objective). The provisional report notes the amount of duct cells and stromal cells present, stating whether the duct cells appear benign, suspicious, or conclusively malignant.

Next day, in the main cytology laboratory, the Diff Quik stained smears are re-examined and the findings compared with the Papanicolaou stained direct smears and saline preparations. Essential clinical findings provided on the cytology form (fig 2) are consulted, and a final report is issued.

If the specimens contain adequate material, they are graded on the 1-5 Papanicolaou scale: grade (1) normal, (2) hyperplastic duct cells, (3) irregularly proliferating duct cells-suspicious of malignancyadvise biopsy, (4) cells highly suspicious of malignancy-advise confirmation by biopsy, and (5) conclusive evidence of malignancy.

Other sindings noted are nuclear enlargement, variation in cell size, increase in number and size of the nucleoli, and lack of cohesion of the tumour fragments.

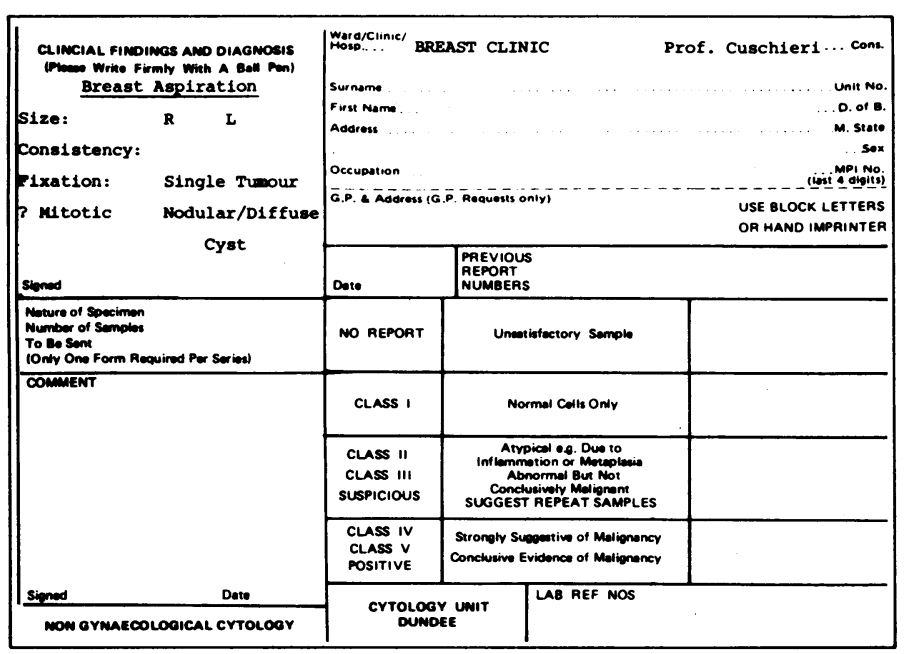

FIG 2-Cytology form.

\section{Results}

In the year ending April 1978, 294 needle aspirations were undertaken. In those patients who were subjected to excision biopsy the diagnosis was finalised either by frozen section or paraffin histology, depending on the degree of suspicion raised on clinical, cytological, or mammographic grounds. Where surgical intervention was not considered necessary, the diagnosis was finally assessed after a follow-up of at least six months. The clinical assessment and cytological findings at the time of presentation are shown in table I.
TABLE I-Clinical and cytological findings

\begin{tabular}{|c|c|c|c|c|c|}
\hline \multirow{2}{*}{ 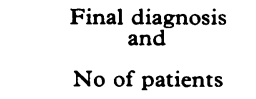 } & \multicolumn{3}{|c|}{ Original clinical diagnosis } & \multirow{2}{*}{\multicolumn{2}{|c|}{$\begin{array}{c}\text { Provisional } \\
\text { cytology report }\end{array}$}} \\
\hline & Benign & Suspicious & Malignant & & \\
\hline Breast cancer : 60 & 3 & $\begin{array}{l}1 \\
1 \\
1 \\
2\end{array}$ & $\begin{array}{r}1 \\
1 \\
5 \\
45\end{array}$ & $\begin{array}{l}\text { Unsatisfactory } \\
\text { Benign } \\
\text { Suspicious } \\
\text { Positive }\end{array}$ & $\begin{array}{r}2 \\
2 \\
6 \\
50\end{array}$ \\
\hline Diffuse nodularity: 106 & $\begin{array}{r}27 \\
71 \\
5\end{array}$ & 2 & 1 & $\begin{array}{l}\text { Unsatisfactory } \\
\text { Benign }\end{array}$ & $\begin{array}{l}20 \\
27 \\
74\end{array}$ \\
\hline Single tumour: 84 & $\begin{array}{r}5 \\
6 \\
52 \\
4 \\
44\end{array}$ & $\begin{array}{l}1 \\
4 \\
5\end{array}$ & $\begin{array}{l}1 \\
7 \\
4\end{array}$ & $\begin{array}{l}\text { Suspicious } \\
\text { Unsatisfactory } \\
\text { Benign } \\
\text { Suspicious } \\
\text { Benign }\end{array}$ & $\begin{array}{r}5 \\
8 \\
63 \\
13 \\
44\end{array}$ \\
\hline
\end{tabular}

\section{CANCER}

Of the 60 patients with breast cancer, 40 underwent biopsy with immediate histological confirmation by frozen section. The remainder had either locally advanced breast cancer or overt metastatic disease. Histological confirmation, when considered desirable, was achieved by a tru-cut biopsy.

The aspirates of three patients, considered on clinical grounds to have benign lesions, provided evidence of malignancy at the first clinic visit $(5 \%)$. The unsatisfactory sample rate of patients with breast cancer and the false-negative rate for cytology were both $2 / 60(3.3 \%)$. On review, one of these aspirates was found to be a poorly cellular sample from an intraduct carcinoma and, in the other, suspicious cells were identified in the Papanicolaou preparations. Six cases were suspicious and 50 were unequivocally positive, no false-positive reports occurring.

\section{DIFFUSE NODULARITY}

The clinical assessment and the provisional cytology findings at the time of presentation of patients with diffuse nodularity are shown in table I. The unsatisfactory sample rate for needle cytology in this group was $27 / 106(25.5 \%)$. A histological diagnosis was obtained in 26 of these 106 because of clinical, mammographic, or cytological suspicion of malignancy or failure to obtain a satisfactory cytological sample after repeat breast aspiration. The histological diagnoses of these lesions are shown in table II. There were no positive (grade 4-5) results, but five were regarded as suspicious (grade 3 ) on cytological grounds $(4 \cdot 7 \%)$. All five cases were confirmed as benign by excision and histological examination (mastopathy 3, sclerosing adenosis 1 , duct ectasia 1).

TABLE II-Histological diagnosis of benign lesions

\begin{tabular}{|c|c|c|c|c|c|}
\hline \multirow[b]{2}{*}{ Group } & \multirow{2}{*}{$\begin{array}{l}\text { No of } \\
\text { cases }\end{array}$} & \multicolumn{4}{|c|}{ Histological diagnosis } \\
\hline & & Fibroadenoma & Mastopathy & $\begin{array}{l}\text { Sclerosing } \\
\text { adenosis }\end{array}$ & $\begin{array}{c}\text { Duct } \\
\text { ectasia }\end{array}$ \\
\hline $\begin{array}{l}\text { Diffuse nodularity } \\
\text { Single tumour } \\
\text { Cystic disease }\end{array}$ & $\begin{array}{l}26 \\
56 \\
16\end{array}$ & 28 & $\begin{array}{l}24 \\
26 \\
15\end{array}$ & $\begin{array}{l}1 \\
1\end{array}$ & $\begin{array}{l}1 \\
1 \\
1\end{array}$ \\
\hline
\end{tabular}

\section{SINGLE TUMOURS}

Of the 84 patients with single tumours, 56 were subjected to excision biopsy and definitive histology (table II). The remaining 28 were carefully followed up for periods of six to 12 months, and judged as benign thereafter. The clinical assessment and the provisional cytological findings at the time of presentation are shown in table I. The unsatisfactory sample rate was $8 / 84(9.5 \%)$. There was no positive cytology in this group, although $13(15.5 \%)$ were regarded as suspicious but confirmed as benign on histology.

\section{CYSTS}

All 44 cystic lesions were correctly classed as benign on cytology (table I), and 16 patients in this group underwent excision biopsy for either persistence or recurrence of the lump (table II). The remaining 28 patients had no recurrence during the period of followup. 


\section{Discussion}

Franzen and Zajicek $^{1}$ reported the results of 2937 breast aspirations. Most centres undertaking fine needle aspiration of the breast follow their method of aspiration and smear preparation. The material can either be air dried and stained with Giemsa, May Grünwald-Giemsa, or wet fixed and stained by the Papanicolaou method. To give immediate staining, we replaced the Giemsa with Diff Quik stain. A direct comparison between Diff Quik and Papanicolaou was not possible, as those slides containing most tissue fragments were air dried and stained by Diff Quik, the less cellular being wet fixed and stained Papanicolaou. The reason for this procedure is that the cells are flattened during air drying thereby emphasising the diagnostic features of malignancy, which are themselves related to the aggressiveness of the tumour. ${ }^{8}$ Papanicolaou staining shows the chromatin pattern of the nucleus, but as the cells tend to be fixed in their normal rounded shape the other characteristics of malignancy are less obvious.

\section{COMPARISON OF PROVISIONAL AND FINAL REPORTS}

The final cytological report clarified the diagnosis in seven benign cases during the earlier part of the series, where duct cells were found only in the centrifuged saline preparations. In one malignant case suspicious cells were seen only in the Papanicolaou-stained smear.

The main value of the final report, however, lies in the further study of the suspicious smear. A provisional "suspicious" report is made when scanty cells showing criteria of malignancyare scattered among normal or atypical epithelial elements. ${ }^{1}$ Before the final report is issued the overall cell picture is reviewed taking into account the clinical findings. Eighteen smears from benign lesions were provisionally labelled as suspicious. The final report suggested mastopathy in seven, fibroadenoma in three, and adenosis associated with pregnancy or oral contraception in two. In the cases of adenosis the lump had disappeared on follow-up examination, and no excisional biopsy was undertaken.

\section{UNSATISFACTORY AND FALSE-NEGATIVE REPORTS}

Unsatisfactory aspirates contain few or no ductal cells and are most often found with benign lesions. Thomas $e t$ al ${ }^{4}$ reported an unsatisfactory rate of $18.9 \%$ for the whole group of cases studied, the rate for benign being double that for malignant tumours. Franzen and Zajicek ${ }^{1}$ reported an unsatisfactory rate of $11.9 \%$ in benign conditions and $3.3 \%$ in malignant. Our unsatisfactory rate for benign breast disease was $35 / 234(15 \%)$ and for carcinomas $2 / 60(3.3 \%)$. We also found that normal breast tissue and breast tissue with no epithelial proliferation almost invariably produce unsatisfactory samples. In contrast, fibroadenomas usually provide very cellular samples, as do carcinomas, with the exception of those tumours that are so hard they are physically difficult to aspirate.

Undoubtedly when an unsatisfactory aspiration is repeated an adequate sample is often obtained. ${ }^{19}$ The practice of reporting satisfactory samples when breast stroma only is present may be dangerous as it could support an incorrect diagnosis, while a label of unsatisfactory might lead to an early excision biopsy. Our practice is to report on the quality of the specimen, assessing the amount of duct cells and stroma as abundant, adequate, poor, or absent. Repeat aspirations are done immediately when considered necessary.

In the breast clinic we have found that failure to"maintain suction when the needle is traversing the lesion leads to poorly cellular samples and that a more cellular sample is obtained when suction is maintained during removal of the needle from the breast. Since we developed the technique of wetting the inside of the needle with saline-heparin solution, the cellularity of the direct smears has definitely improved, and we now find that, unless the aspirate is copious, the final saline wash preparations almost invariably contain no cells.

\section{FALSE-NEGATIVE SAMPLES}

In most false-negative samples the aspirate from a malignant breast does not contain tumour cells but duct cells from surrounding tissue, the reasons usually quoted being small or hard tumours that are not penetrated by the needle. Sometimes tumour cells are not recognised by the cytologist-especially small-cell carcinomas and carcinomas of unusual type. ${ }^{10}$ The four failed aspirations in our series of 60 carcinomas all came from cases with hard mobile tumours, one of which was sited deeply within the breast tissue. As advised by Franzen, ${ }^{1}$ we now keep a supply of larger, wider disposable needles (20 gauge, $7.5 \mathrm{~cm}$ long) for use in difficult cases.

\section{VALUE OF DIRECT REPORTING TO THE SURGEON}

A report of conclusive evidence of malignancy at the first clinic visit allows the surgeon to have a positive discussion with the patient about the investigations and possible outcome of her breast condition. Metastatic surveys are ordered so that results are available by the time of admission for use in deciding the appropriate management. In the elderly and those whose physical condition does not warrant the use of a general anaesthetic, cytology provides the morphological diagnosis of carcinoma, which is necessary before treatment can be carried out.

By this technique also the management of patients with benign disease has been advanced.' When clinical diagnosis of a benign lesion is supported by normal cytological findings, the patient is told that an $x$-ray film of the breast is necessary and she will be seen again but at present the condition is not considered to be serious. Our policy is that when either ${ }^{11}$ physical examination, aspiration cytology, or mammography is suspicious urgent removal with frozen section is arranged. We also remove single breast tumours that persist on follow-up. In this way the overall diagnostic error-that is, number of missed malignancies -is less than $1 \% .{ }^{12}$

In our series of 44 breast cysts 16 had a residual mass or developed recurrence of the cyst fluid. Aspiration was not followed by recurrence in 28 patients $(63 \%)$ during the period of study.

Some surgeons undertake aspiration cytology only on single tumours or masses that are thought clinically to be malignant. ${ }^{13}$ Since $5 \%$ of clinically benign lesions have proved malignant, even on immediate reporting, we would recommend cytological examination of all breast lumps.

We thank Mrs Elizabeth Evans for cytological assistance at the breast clinic.

Requests for reprints should be addressed to AC.

\section{References}

1 Franzen, S, and Zajicek, J, Acta Radiologica, 1968, 7, 242.

2 Webb, A J, British fournal of Surgery, 1970, 57, 259.

${ }^{3}$ Coleman, D, et al, Clinical Oncology, 1975, 1, 27.

4 Thomas, J M, et al, British Medical fournal, 1978, 2, 1139.

${ }^{5}$ British Medical fournal, 1978, 1, 1507.

${ }^{6}$ Lopez Cardoso, P, Atlas of Clinical Cytology. Netherlands, Targa BVs Hertogenbosch, 1973.

7 Mazia, D, Schatten, G, and Sale, W, Fournal of Cell Biology, 1975, 66, 198

8 Wallgreen, A, and Zajicek, J, Acta Cytologica, 1976, 20, 479.

9 Schondorf, $\mathrm{H}$, Aspiration Cytology of the Breast. Philadelphia and London, W B Saunders, 1978.

10 Kreuzer, G, and Zajicek, J, Acta Cytologica, 1972, 16, 249.

11 Van Bogaert, L J, and Mazy, G, Acta Cytologica, 1977, 21, 60.

12 Kreuzer, G, and Boquoi, E, Acta Cytologica, 1976, 20, 319.

${ }^{13}$ British Medical fournal, 1977, 2, 282.

(Accepted 23 May 1979) 